\title{
HBsAg Loss with Peg-interferon Alfa-2a in Hepatitis B Patients with Partial Response to Nucleos(t)ide Analog: New Switch Study
}

\author{
Peng $\mathrm{Hu}^{\# 1}$, Jia Shang ${ }^{\# 2}$, Wenhong Zhang ${ }^{\# 3}$, Guozhong Gong ${ }^{4}$, Yongguo $\mathrm{Li}^{5}$, Xinyue Chen ${ }^{6}$, \\ Jianning Jiang ${ }^{7}$, Qing Xie ${ }^{8}$, Xiaoguang Dou ${ }^{9}$, Yongtao Sun ${ }^{10}$, Yufang $\mathrm{Li}^{11}$, Yingxia Liu ${ }^{12}$, \\ Guozhen Liu ${ }^{13}$, Dewen Mao ${ }^{14}$, Xiaoling Chi ${ }^{15}$, Hong Tang ${ }^{16}$, Xiaoou $\mathrm{Li}^{17}$, Yao Xie ${ }^{18}$, \\ Xiaoping Chen ${ }^{19}$, Jiaji Jiang ${ }^{20}$, Ping Zhao ${ }^{21}$, Jinlin Hou ${ }^{22}$, Zhiliang Gao ${ }^{23}$, Huimin Fan ${ }^{24}$, \\ Jiguang Ding ${ }^{25}$, Dazhi Zhang ${ }^{1}$ and Hong Ren*1
}

\begin{abstract}
${ }^{1}$ Department of Infectious Diseases, The Second Affiliated Hospital of Chongqing Medical University, Chongqing, China; ${ }^{2}$ Department of Infectious Diseases, Henan Provincial People's Hospital, Zhengzhou, China; ${ }^{3}$ Department of Infectious Diseases, Huashan Hospital, Fudan University, Shanghai, China; ${ }^{4}$ Department of Infectious Diseases, The Second Xiangya Hospital of Central South University, Changsha, China; ${ }^{5}$ Department of Infectious Diseases, The First Affiliated Hospital of Harbin Medical University, Harbin, China; ${ }^{6}$ International Medical Department, Beijing YouAn Hospital, Capital Medical University, Beijing, China; ${ }^{7}$ Department of Infectious Diseases, The First Affiliated Hospital of Guangxi Medical University, Nanning, China; ${ }^{8}$ Department of Infectious Diseases, Ruijin Hospital, Shanghai Jiaotong University School of Medicine, Shanghai, China; ${ }^{9}$ Department of Infectious Diseases, Shengjing Hospital of China Medical University, Shenyang, China; ${ }^{10}$ Department of Infectious Diseases, Tangdu Hospital, Fourth Military Medical University, Xi'an, China; ${ }^{11}$ Department of Infectious Diseases, General Hospital of Ningxia Medical University, Yinchuan, China; ${ }^{12}$ Department of Infectious Diseases, Shenzhen Third People's Hospital, Shenzhen, China; ${ }^{13}$ Department of Infectious Diseases, Xiangya Hospital Central South University, Changsha, China; ${ }^{14}$ Liver Disease Department, The First Affiliated Hospital of Guangxi University of Chinese Medicine, Nanning, China; ${ }^{15}$ Liver Disease Department, Guangdong Hospital of Traditional Chinese Medicine, Guangzhou, China; ${ }^{16}$ Center of Infectious Diseases, West China Hospital, Sichuan University, Chengdu, China; ${ }^{17}$ Liver Disease Department, The Sixth People's Hospital of Hangzhou, Zhejiang, China; ${ }^{18}$ Liver Disease Department, Beijing Ditan Hospital, Capital Medical University, Beijing, China; ${ }^{19}$ Department of Infectious Diseases,

Guangdong General Hospital, Guangzhou, China; ${ }^{20}$ Center of Liver Diseases, The First Affiliated Hospital of Fujian Medical University, Fuzhou, China; ${ }^{21}$ International Center for Liver Disease Treatment, 302 Hospital of PLA, Beijing, China; ${ }^{22}$ Department of Infectious Diseases and Hepatology Unit, Nanfang Hospital, Southern Medical University, Guangzhou, China; ${ }^{23}$ Department of Infectious Diseases, The Third Affiliated Hospital of Sun Yat-Sen University, Guangzhou, China; ${ }^{24}$ Hepatology Unit, Guangzhou Eighth People's Hospital, Guangzhou, China; ${ }^{25}$ Hepatology Unit, Ruian People's Hospital, Zhejiang, China
\end{abstract}

\begin{abstract}
Background and Aims: Hepatitis B surface antigen (HBsAg) loss is seldom achieved with nucleos(t)ide analog (NA) therapy in chronic hepatitis $B$ patients but may be enhanced by switching to finite pegylated-interferon (Peg-IFN) alfa-2a. We assessed HBsAg loss with 48- and 96-week Peg-IFN alfa-2a in chronic hepatitis $B$ patients with partial response to a previous NA. Methods: Hepatitis B e antigen (HBeAg)-positive patients who achieved HBeAg loss and hepatitis $B$ virus DNA $<200 \mathrm{IU} / \mathrm{mL}$ with previous adefovir, lamivudine or entecavir treatment were randomized $1: 1$ to receive Peg-IFN alfa-2a for $48(n=153)$ or 96 weeks $(n=150)$. The primary endpoint of this study was HBsAg loss at end of treatment. The
\end{abstract}

Keywords: Antiviral therapy; Peg-interferon; Nucleos(t)ide treated; Chronic hepatitis $B$.

Abbreviations: ALT, alanine aminotransferase; AST, aspartate aminotransferase; $\mathrm{CHB}$, chronic hepatitis $\mathrm{B}$; $\mathrm{HBeAg}$, hepatitis $\mathrm{B}$ e antigen; $\mathrm{HBsAg}$, hepatitis $\mathrm{B}$ surface antigen; HBV, hepatitis $B$ virus; ITT, intention-to-treat; LOCF, last observation carried forward; NA, nucleos(t)ide analog; Peg-IFN, pegylated-interferon; PP, per protocol; SD, standard deviation; ULN, upper limit of normal.

Received: 5 November 2017; Revised: 24 January 2018; Accepted: 1 March 2018 \#These authors contributed equally to this study.

*Correspondence to: Hong Ren, Department of Infectious Diseases, The Second Affiliated Hospital of Chongqing Medical University, Chongqing 400010, China. Tel: +86-23-63693029, Fax: +86-23-63711527, E-mail: renhong0531@vip.sina.com.cn
ClinicalTrials.gov identifier is NCT01464281. Results: At the end of 48 and 96 weeks' treatment, $14.4 \%(22 / 153)$ and $20.7 \%(31 / 150)$ of patients, respectively, who switched from NA to Peg-IFN alfa-2a cleared HBsAg. Rates were similar irrespective of prior NA or baseline HBeAg seroconversion. Among those who cleared HBsAg by the end of 48 and 96 weeks' treatment, $77.8 \%$ (14/18) and 71.4\% (20/28), respectively, sustained HBsAg loss for a further 48 weeks. Baseline $\mathrm{HBsAg}<1500 \mathrm{IU} / \mathrm{mL}$ and week $24 \mathrm{HBsAg}<200 \mathrm{IU} / \mathrm{mL}$ were associated with the highest rates of HBsAg loss at the end of both 48 - and 96 -week treatment (51.4\% and 58.7\%, respectively). Importantly, extending treatment from 48 to 96 weeks enabled $48.3 \%(14 / 29)$ more patients to achieve HBsAg loss. Conclusions: Patients on long-term NA who are unlikely to meet therapeutic goals can achieve high rates of HBsAg loss by switching to Peg-IFN alfa-2a. HBsAg loss rates may be improved for some patients by extending treatment from 48 to 96 weeks, although the differences in our study cohort were not statistically significant. Baseline and on-treatment $\mathrm{HBsAg}$ may predict HBsAg loss with Peg-IFN alfa-2a.

Citation of this article: Hu P, Shang J, Zhang W, Gong G, Li Y, Chen $X$, et al. HBsAg loss with peg-interferon alfa-2a in hepatitis $B$ patients with partial response to nucleos(t)ide analog: new switch study. J Clin Transl Hepatol 2018;6(1):25-34. doi: 10.14218/JCTH.2017.00072. 
Hu P. et al: High HBsAg loss rates by switching to Peg-IFN

\section{Introduction}

Hepatitis B virus (HBV)-related morbidities cause $0.5-1.0$ million deaths yearly and remain a major public health concern, ${ }^{1}$ especially in China, where HBV infection is endemic. A national survey carried out in China in 2006 showed a $7.18 \%$ rate of hepatitis B surface antigen ( $\mathrm{HBsAg}$ ) positivity among people under 60 years of age, accounting for more than one-third of all chronic HBV infections globally at the time. ${ }^{2,3}$

International guidelines recommend treating hepatitis $B$ e antigen ( $\mathrm{HBeAg})$-positive chronic hepatitis $\mathrm{B}(\mathrm{CHB})$ with a finite course of pegylated-interferon (Peg-IFN) or long-term treatment with nucleos(t)ide analogs (NAs). ${ }^{1,4,5}$ Although potent NAs can suppress virological replication on treatment, relapse is common upon treatment discontinuation. Virological relapse 1 year after NA discontinuation has been demonstrated in up to $71 \%$ of $\mathrm{HBeAg}$-positive patients who achieve HBeAg seroconversion on treatment, and $90 \%$ of $\mathrm{HBeAg}$-negative patients who maintain virological suppression on therapy; consolidation therapy for at least a year decreases, but does not eliminate, the risk for relapse. ${ }^{6-11}$

Functional cure, whereby the state of health is returned such that liver-related mortality risk is the same as that for a naturally resolved chronic infection, 12 is associated with improved liver histology and survival. ${ }^{13,14}$ Functional cure entails assessment of markers including HBsAg loss, ${ }^{12}$ which is considered the closest state to a cure and an ideal therapeutic endpoint. ${ }^{1}$

HBsAg loss rates over time are generally higher with Peg-IFN than with NAs. HBsAg loss rate is 3-7\% after 1 year of treatment with Peg-IFN ${ }^{15,16}$ and can increase to up to $12 \% 5$ years posttreatment. ${ }^{17}$ It is uncommon for NA-treated patients to achieve HBsAg loss; it has been suggested that it may take up to 52.2 years of NA treatment to clear HBsAg. ${ }^{18}$ As such, new treatment strategies for optimizing HBsAg loss in NA-treated patients are required.

Adding or switching to Peg-IFN in NA-treated patients has been demonstrated to improve outcomes. The OSST study showed that it is possible to enhance chances of HBsAg loss in NA-treated HBeAg-positive patients by switching to a finite course of Peg-IFN alfa-2a therapy. In the study, $8.5 \%$ of patients who switched from long-term entecavir to 48-week Peg-IFN alfa-2a achieved HBsAg loss, compared with $0 \%$ of those who continued on entecavir. ${ }^{19}$ Among $\mathrm{HBeAg}$-positive patients, $\mathrm{HBeAg}$ loss is associated with increased likelihood of subsequent HBsAg loss during or after Peg-IFN alfa-2a treatment. ${ }^{19,20}$ Lampertico et al. ${ }^{21}$ showed that extending Peg-IFN treatment from 48 to 96 weeks improved HBsAg clearance rate in HBeAg-negative genotype $D$ patients, while Zhu et al. ${ }^{22}$ demonstrated significantly higher HBsAg loss rates with 72 weeks of Peg-IFN alfa$2 \mathrm{a}$ in $\mathrm{HBeAg}$-positive patients compared with 48 weeks.

While these studies have evaluated the impact of adding or switching to Peg-IFN in NA-treated patients, none have studied HBsAg loss as the primary endpoint. The current 'New Switch' study aims to evaluate HBsAg loss rates with 48- and 96-week Peg-IFN alfa-2a in CHB patients with partial response to a previous NA.

\section{Methods}

\section{Study participants and design}

This was a Phase IV, open-label, randomized study conducted at 25 centers in China. Patients aged $18-65$ years who were HBeAg-positive, had been HBsAg-positive for $\geq 6$ months prior to initial NA treatment, were treated with a NA (adefovir, entecavir or lamivudine) for $1-3$ years, and had achieved partial response (HBV DNA $<200 \mathrm{IU} / \mathrm{mL}$ and $\mathrm{HBeAg}$ loss, including patients who had achieved $\mathrm{HBeAg}$ seroconversion) were eligible. None of the patients had HBsAg cleared with NA treatment. Patients who had been pre-treated with other antiviral or immunomodulatory agents, including interferon, within 1 year prior to enrollment were excluded, as were patients who were co-infected with human immunodeficiency virus or hepatitis $A$, $C$ or D, as well as patients with a history or evidence of chronic liver disease associated with another medical condition or decompensated liver disease (Child-Pugh score $\geq 5$ ).

Patients were randomized $1: 1$ to receive Peg-IFN alfa-2a at $180 \mu \mathrm{g} /$ week for 48 or 96 weeks, and stratified according to prior NA therapy (lamivudine, entecavir or adefovir) and baseline HBsAg level ( $\leq 3000 \mathrm{IU} / \mathrm{mL}$ vs. $>3000 \mathrm{IU} / \mathrm{mL}$ ), with a block size of 4 . Randomization was done centrally through a computer-generated random allocation sequence. All patients received an initial 12-week overlap of both Peg-IFN alfa-2a and the prior NA, and were followed up for 48 weeks posttreatment. The study was performed in accordance with Good Clinical Practice and the ethical principles of the Declaration of Helsinki (ClinicalTrials.gov: NCT01464281). The study protocol was approved by a central independent ethics committee from The Second Affiliated Hospital of Chongqing Medical University. All patients provided written informed consent. All authors had access to the study data and reviewed and approved the final manuscript.

\section{Laboratory measurements}

Patients were assessed at screening, weeks 0, 4 and 12, and every 12 weeks thereafter until 48 weeks post-treatment. Serum HBsAg and $\mathrm{HBeAg}$ levels were measured by quantitative assay using the modular E170 analyzer (Roche Diagnostics, Basel, Switzerland; HBsAg range of 0.05 to $52,000 \mathrm{IU} / \mathrm{mL}$ and $\mathrm{HBeAg}$ cut-off index $<0.2 \mathrm{PE} \mathrm{IU} / \mathrm{mL}$ ), hepatitis B surface antibody and hepatitis $B$ e antibody with enzyme-linked immunosorbent assay kits (Kehua Biotechnology, Shanghai, China), and HBV DNA with the Cobas ${ }^{\circledR}$ TaqMan $^{\circledR}$ HBV test (Roche Diagnostics; range of $20 \mathrm{IU} / \mathrm{mL}$ to $1.7 \times 10^{8} \mathrm{IU} / \mathrm{mL}$ ) at a central laboratory.

Reporting of adverse events and recording of laboratory tests conformed to the International Conference on Harmonisation Guidelines for Clinical Safety Data Management: Definitions and Standards for Expedited Reporting.

\section{Statistical analysis}

The primary endpoint was HBsAg loss at the end of treatment (weeks 48 and 96). Secondary endpoints included HBsAg loss and seroconversion at the end of 48-week follow-up, as well as HBsAg kinetics, HBeAg seroconversion, maintained HBeAg loss, HBV DNA <200 IU/mL, and alanine aminotransferase (ALT) normalization (ALT level $\leq 1 \times$ upper limit of normal [ULN]) at the end of treatment and at the end of 48-week follow-up.

All patients who received at least one dose of study medication were included in the intention-to-treat (ITT) and safety analyses. Patients who satisfied all key study inclusion and exclusion criteria, received at least $80 \%$ of study medication, and completed the study without major protocol deviation were included in the per protocol (PP) analysis.

HBsAg loss rate in NA-treated patients who achieved partial response was assumed to be $15 \%$ and $30 \%$, and dropout rates 
would be $15 \%$ and $20 \%$, for the 48 - and 96 -week treatment arms, respectively. Based on these assumptions, a sample size of 150 per group was determined to be adequate to provide a statistical power of at least $80 \%$ for demonstrating superiority of the 96-week over the 48-week treatment.

Response rates were summarized using descriptive statistics by calculating percentages. Patients with missing categorical data were classified as non-responders. No imputation was conducted for missing continuous variable data. Exploratory sensitivity analysis of the primary endpoint was performed using the last observation carried forward (LOCF) imputation method for the ITT population. All statistical tests were twosided and were evaluated at the 0.05 level of significance. Statistical analyses were conducted with SAS version 9.1.3 (SAS Institute, Cary, NC, USA).

\section{Results}

\section{Patient demographics and baseline characteristics}

From October 2011, 305 patients were enrolled and randomized in the study. Among them, 154 were assigned to 48week Peg-IFN alfa-2a and 151 to 96 -week Peg-IFN alfa-2a. One patient in each arm did not receive the study drug; both were excluded from the final analysis (Fig. 1).

Baseline demographics and characteristics were similar between the two arms (Table 1 ). At baseline, $57 \%$ of patients in both arms had achieved HBeAg seroconversion. Patients were treated with a prior NA for a mean of 2.1 years in the 48-week treatment arm and 2.2 years in the 96-week treatment arm. Entecavir was the most common prior NA, followed by adefovir and lamivudine. Most patients (83\%) had an aspartate aminotransferase-to-platelet ratio index score below 0.5 and none of the patients had cirrhosis.

\section{Efficacy}

Response rates at the end of Peg-IFN alfa-2a treatment

More patients who received 96-week Peg-IFN alfa-2a treatment achieved the primary endpoint of HBsAg loss than those who received 48-week Peg-IFN alfa- $2 a$ at the end of treatment (20.7\% vs. $14.4 \% ; p=0.1742$ ) and at the end of follow-up ( $15.3 \%$ vs. $9.8 \% ; p=0.1670)$, although between-group differences were not statistically significant (Table 2 ).

Response was similar in the PP analysis, with $24.1 \%$ (26/ $108)$ and $16.8 \%(17 / 101)$ of patients who received $96-$ and $48-$ week Peg-IFN alfa-2a treatment, respectively, achieving HBsAg loss at the end of treatment. Findings were also consistent with those of a LOCF sensitivity analysis of the ITT population (Table 2).

Similarly, HBsAg seroconversion rates were higher among patients treated with Peg-IFN alfa-2a for 96 weeks compared with those treated for 48 weeks, both at the end of treatment $(16.0 \%$ vs. $13.1 \% ; p=0.5163)$ and at the end of follow-up (12.0\% vs. $9.2 \% ; p=0.4586)$, although differences were not statistically significant. HBeAg seroconversion rates decreased slightly from baseline to the end of 48 -week treatment $(56.9 \%$

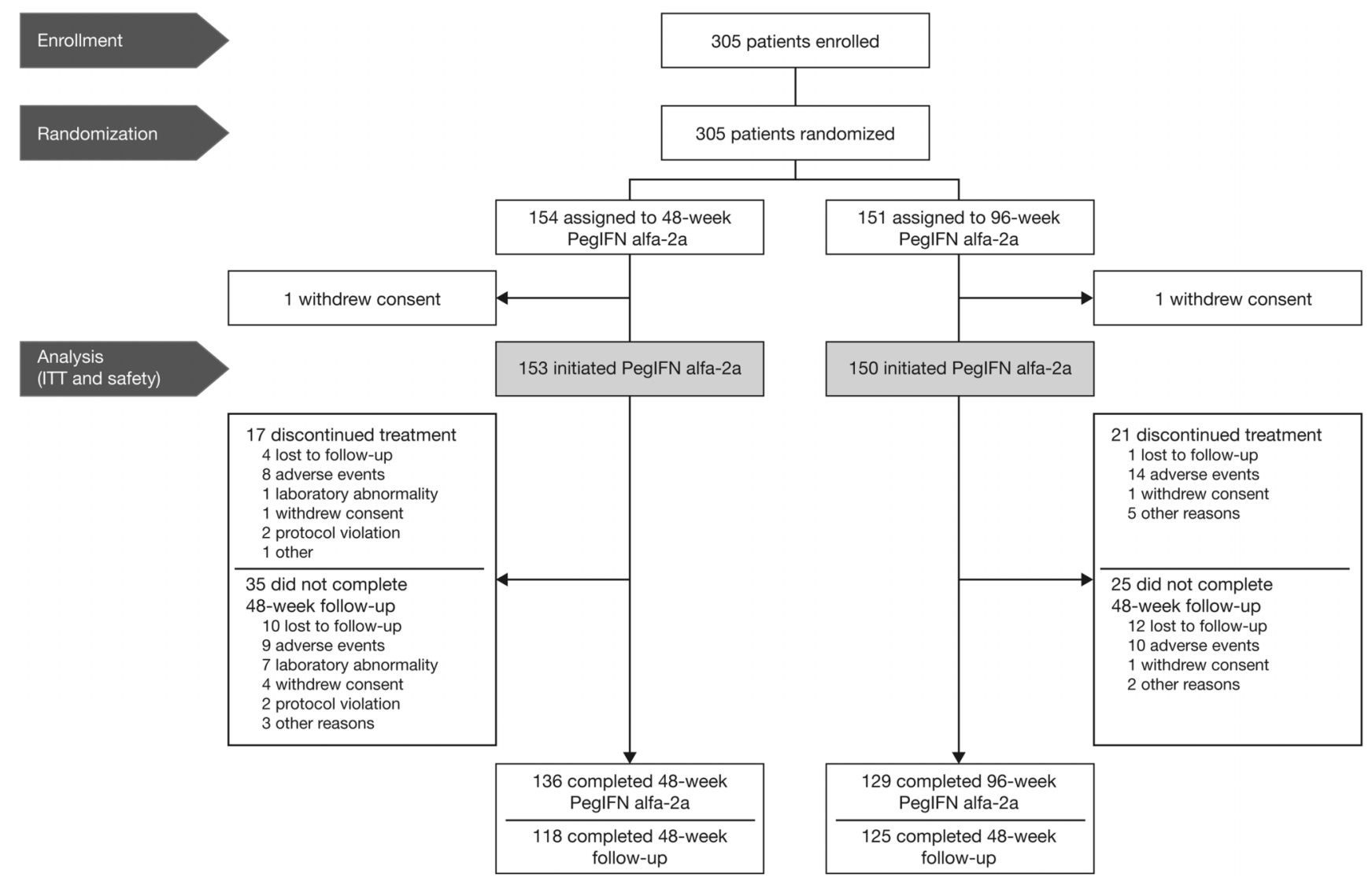

Fig. 1. Patient disposition. Abbreviations: ITT, intention-to-treat; Peg-IFN, pegylated-interferon. 
Hu P. et al: High HBsAg loss rates by switching to Peg-IFN

\begin{tabular}{|c|c|c|}
\hline & $\begin{array}{l}\text { 48-week Peg-IFN } \\
\text { alfa-2a, } n=153\end{array}$ & $\begin{array}{l}\text { 96-week Peg-IFN } \\
\text { alfa-2a, } n=150\end{array}$ \\
\hline Male, $n(\%)$ & $126(82.4)$ & $120(80.0)$ \\
\hline Mean age, years (SD) & $35.1(10.0)$ & $33.3(8.8)$ \\
\hline Mean weight, kg (SD) & $66.0(11.3)$ & $64.8(11.1)$ \\
\hline Mean duration of diagnosed HBV infection, years (SD) & $10.0(7.0)$ & $10.0(6.10)$ \\
\hline \multicolumn{3}{|l|}{ Prior NA, $n(\%)$} \\
\hline Lamivudine & $42(27.5)$ & $42(28.0)$ \\
\hline Entecavir & $58(37.9)$ & $56(37.3)$ \\
\hline Adefovir & $53(34.6)$ & $52(34.7)$ \\
\hline Mean duration of prior NA treatment, years (SD) & $2.1(0.6)$ & $2.2(0.6)$ \\
\hline Median HBsAg, $\log _{10} \mathrm{IU} / \mathrm{mL}$ (IQR) & $3.2(2.9-3.6)$ & $3.2(2.8-3.6)$ \\
\hline HBeAg seroconversion, $n(\%)$ & $87(56.9)$ & $86(57.3)$ \\
\hline Mean HBV DNA, $\log _{10} \mathrm{IU} / \mathrm{mL}(\mathrm{SD})$ & $1.4(0.2)$ & $1.4(0.2)$ \\
\hline \multicolumn{3}{|l|}{ APRI score, $n(\%)$} \\
\hline$<0.5$ & $127(83.0)$ & $124(82.7)$ \\
\hline $0.5-<1.0$ & $24(15.7)$ & $24(16.0)$ \\
\hline $1.0-<1.5$ & $1(0.7)$ & $2(1.3)$ \\
\hline $1.5-2.0$ & $1(0.7)$ & 0 \\
\hline$\geq 2.0$ & 0 & 0 \\
\hline Normal ALT (<ULN), n (\%) & $138(90.2)$ & $142(94.7)$ \\
\hline Mean ALT, IU/L (SD) & $25.5 \pm 16.3$ & $24.6 \pm 13.2$ \\
\hline
\end{tabular}

Abbreviations: ALT, alanine aminotransferase; APRI, aspartate aminotransferase-to-platelet ratio index; HBV, hepatitis B virus; NA, nucleos(t)ide analog; IQR, interquartile range; Peg-IFN, pegylated-interferon; SD, standard deviation; ULN, upper limit of normal.

[87/153] to $54.9 \%$ [84/153]) and increased slightly from $57.3 \%(86 / 150)$ at baseline to $60.7 \%(91 / 150)$ after 96 weeks of treatment (Table 2).

With both treatment durations, approximately three out of four patients maintained HBV DNA suppression at the end of Peg-IFN alfa-2a treatment (Table 2). Four and 11 patients experienced virological relapse after 48 and 96 weeks of treatment, respectively; one of these patients in the 96-week arm experienced a clinical relapse (HBV DNA > $2000 \mathrm{IU} / \mathrm{mL}$ and ALT $>2 \times$ ULN).

Impact of previous NA and baseline hepatitis B e antibody on HBsAg loss at week 48

When evaluating the impact of previous NA on HBsAg response with Peg-IFN alfa-2a at week 48, no significant differences were observed between the three NAs. HBsAg loss and seroconversion rates were comparable between patients who switched to Peg-IFN alfa-2a from adefovir (15.2\% and $14.3 \%)$, enteca$\operatorname{vir}(14.0 \%$ and $11.4 \%)$, and lamivudine $(9.5 \%$ and $8.3 \%)$. Similarly, responses were not significantly different between patients who had achieved HBeAg seroconversion before switching to Peg-IFN alfa-2a and those who had not (Supplementary Table 1 ).

Sustained response 48 weeks after Peg-IFN alfa-2a discontinuation

Among patients who achieved HBsAg loss at the end of treatment and had HBsAg data at end of follow-up $(n=46), 77.8 \%$
(14/18) and 71.4\% (20/28) who were treated for 48 and 96 weeks, respectively, sustained HBsAg loss 48 weeks after discontinuing Peg-IFN alfa-2a. Except for one patient with $\mathrm{HBsAg}$ $41.0 \mathrm{IU} / \mathrm{mL}$ and one patient with $\mathrm{HBsAg} 10.41 \mathrm{IU} / \mathrm{mL}, \mathrm{HBsAg}$ levels remained below $10 \mathrm{IU} / \mathrm{mL}$ in all patients who did not sustain HBsAg loss at end of follow-up. All except one patient maintained virological suppression (HBV DNA <200 IU/mL) 48 weeks off treatment, and none experienced virological relapse (HBV DNA $>2000 \mathrm{IU} / \mathrm{mL})$. All patients had normal ALT $(<1 \times$ ULN) at 48 weeks after treatment discontinuation, except three patients with ALT levels between 1 and $2 \times$ ULN (Fig. 2). Among the 46 responders who had data at end of follow-up, 12 experienced HBsAg relapse during the 48 weeks between end of treatment and end of follow-up. Clinical characteristics of these patients at baseline are described in Supplementary Table 2.

In the overall population, significantly more patients treated for 96 weeks maintained virological suppression at 48 weeks after treatment was discontinued than those treated for 48 weeks $(48.7 \%$ vs. $34.6 \% ; p=0.0146)$. After 48 weeks' follow-up, $58.8 \%$ and $69.3 \%$ in the 48 - and 96 -week arms, respectively, maintained ALT normalization, compared with approximately $90 \%$ in both arms at baseline (Table 2 ).

\section{HBsAg kinetics}

In the overall population, mean serum HBsAg level declined from $3.09 \log _{10} \mathrm{IU} / \mathrm{mL}$ at baseline to $2.00 \log _{10} \mathrm{IU} / \mathrm{mL}$ after 48 weeks of Peg-IFN alfa-2a treatment, and from $3.12 \log _{10}$ $\mathrm{IU} / \mathrm{mL}$ to $1.82 \log _{10} \mathrm{IU} / \mathrm{mL}$ after 96 weeks of treatment. 
Hu P. et al: High HBsAg loss rates by switching to Peg-IFN

Table 2. Response at the end of Peg-IFN alfa-2a treatment and at the end of 48-week follow-up (ITT) 48-week Peg-IFN alfa-2a, $n=153$

\begin{tabular}{|c|c|c|c|c|c|c|}
\hline & $\begin{array}{l}\text { 48-week Peg- } \\
\text { IFN alfa-2a, } \\
n=153\end{array}$ & $\begin{array}{l}\text { 96-week Peg- } \\
\text { IFN alfa-2a, } \\
n=150\end{array}$ & $P$ & $\begin{array}{l}\text { 48-week Peg- } \\
\text { IFN alfa-2a, } \\
n=153\end{array}$ & $\begin{array}{l}\text { 96-week Peg- } \\
\text { IFN alfa-2a, } \\
n=150\end{array}$ & $P$ \\
\hline \multicolumn{7}{|l|}{ HBsAg response } \\
\hline HBsAg loss & $22(14.4)$ & $31(20.7)$ & 0.1742 & $15(9.8)$ & $23(15.3)$ & 0.1670 \\
\hline \multicolumn{7}{|c|}{ HBsAg loss sensitivity analysis } \\
\hline $\begin{array}{l}\text { HBsAg loss by LOCF } \\
\text { imputation method }\end{array}$ & $23 / 153(15.0)$ & $35 / 150(23.3)$ & 0.0794 & & & \\
\hline $\begin{array}{l}\text { HBsAg loss by PP } \\
\text { analysis }\end{array}$ & $17 / 101(16.8)$ & $26 / 108(24.1)$ & 0.2319 & & & \\
\hline HBsAg seroconversion & $20(13.1)$ & $24(16.0)$ & 0.5163 & $14(9.2)$ & $18(12.0)$ & 0.4586 \\
\hline \multicolumn{7}{|l|}{ HBeAg response } \\
\hline $\begin{array}{l}\text { Maintained HBeAg } \\
\text { loss }\end{array}$ & $132(86.3)$ & $124(82.7)$ & 0.4293 & $95(62.1)$ & $107(71.3)$ & 0.1129 \\
\hline $\begin{array}{l}\mathrm{HBeAg} \\
\text { seroconversion }\end{array}$ & $84(54.9)$ & $91(60.7)$ & 0.3524 & $78(51.0)$ & $83(55.3)$ & 0.4902 \\
\hline \multicolumn{7}{|l|}{ Virologic response } \\
\hline $\begin{array}{l}\text { Maintained virologic } \\
\text { suppression (HBV } \\
\text { DNA <200 IU/mL) }\end{array}$ & $117(76.5)$ & $111(74.0)$ & 0.6900 & $53(34.6)$ & $73(48.7)$ & 0.0146 \\
\hline $\begin{array}{l}\text { Virologic relapse (HBV } \\
\text { DNA > } 2000 \mathrm{IU} / \mathrm{mL})\end{array}$ & $4(2.6)$ & $11(7.3)$ & 0.0674 & $19(12.4)$ & $24(16.0)$ & 0.4127 \\
\hline \multicolumn{7}{|c|}{ Biochemical response* } \\
\hline $\mathrm{ALT} \leq 1 \times \mathrm{ULN}$ & $76(49.7)$ & $92(61.3)$ & 0.0494 & $90(58.8)$ & $104(69.3)$ & 0.0723 \\
\hline ALT 1 to $\leq 5 \times$ ULN & $61(39.9)$ & $38(25.3)$ & 0.0073 & $16(10.5)$ & $8(5.3)$ & 0.1356 \\
\hline ALT $>5 \times$ ULN & $1(0.7)$ & $2(1.3)$ & 0.6200 & $1(0.7)$ & $1(0.7)$ & 1.0000 \\
\hline
\end{tabular}

* 33 and 83 patients did not have ALT test results at end of treatment and end of follow-up, respectively.

Abbreviations: ALT, alanine aminotransferase; HBeAg, hepatitis B e antigen; HBsAg, hepatitis B surface antigen; HBV, hepatitis B virus; ITT, intention-to-treat; LOCF, last observation carried forward; Peg-IFN, pegylated-interferon; PP, per protocol; ULN, upper limit of normal.

Responders (defined as those who achieved HBsAg loss at the end of treatment) in both treatment groups had significantly lower serum HBsAg at baseline $\left(1.82 \log _{10} \mathrm{IU} / \mathrm{mL}\right.$ vs. $3.30 \log _{10} \mathrm{IU} / \mathrm{mL} ; p<0.0001$ in the 48 -week group, and 2.49 $\log _{10} \mathrm{IU} / \mathrm{mL}$ vs. $3.28 \log _{10} \mathrm{IU} / \mathrm{mL} ; p<0.0001$ in the 96 -week group) and at all time points throughout the study compared with non-responders (Fig. 3). Furthermore, all responders maintained undetectable or very low HBsAg levels at 48 weeks after treatment discontinuation.

Among nonresponders, those treated with Peg-IFN alfa-2a for 96 weeks had significantly lower mean serum HBsAg levels than those treated for 48 weeks (Fig. 3). Importantly, while HBsAg levels increased after treatment discontinuation in both groups, the increase was more marked in patients treated for 48 weeks than in those treated for 96 weeks.

\section{Association between baseline and on-treatment HBsAg and response}

Baseline HBsAg level as predictor of response

Receiver operating characteristic curve analysis was performed to compare the value of HBsAg levels at baseline, week 12 and week 24 as predictors of week $48 \mathrm{HBsAg}$ loss, and to identify optimal cut-offs for response and nonresponse. Baseline HBsAg $<1500 \mathrm{IU} / \mathrm{mL}$ was associated with high rates of HBsAg loss at week 48 of Peg-IFN alfa-2a treatment (Table 3). Significantly more patients with baseline HBsAg $<1500 \mathrm{IU} / \mathrm{mL}$ achieved HBsAg loss at the end of 48-week treatment (26.5\% [18/68] vs. $4.7 \%[4 / 85] ; p=0.0002)$ and 96 -week treatment $(40.0 \%$ $[28 / 70]$ vs. $3.8 \%[3 / 80] ; p=0.0001)$ compared with patients with baseline $\mathrm{HBsAg} \geq 1500 \mathrm{IU} / \mathrm{mL}$.

On-treatment HBsAg levels as predictor of response

Week 24 HBsAg level (area under the concentration-time curve 0.983 , sensitivity $90.0 \%$, specificity $96.7 \%$ ) was a better ontreatment predictor of week $48 \mathrm{HBsAg}$ loss than week $12 \mathrm{HBsAg}$ level (area under the concentration-time curve 0.902, sensitivity $82.5 \%$, specificity $84.7 \%$ ). Furthermore, week $24 \mathrm{HBsAg}$ $\geq 200 \mathrm{IU} / \mathrm{mL}$ was found to be the strongest predictor of nonresponse at week 48 (negative predictive value 100\%). None of the patients with week $24 \mathrm{HBsAg} \geq 200 \mathrm{IU} / \mathrm{mL}$ achieved $\mathrm{HBsAg}$ loss after 48 weeks of treatment, and only $3 \%(3 / 88)$ cleared HBsAg after 96 weeks of treatment (Table 3).

In the overall population, significantly more patients with baseline $\mathrm{HBsAg}<1500 \mathrm{IU} / \mathrm{mL}$ had $\mathrm{HBsAg}$ levels reduced to $<200 \mathrm{IU} / \mathrm{mL}$ at week 24 compared with those who initiated treatment with $\mathrm{HBsAg} \geq 1500 \mathrm{IU} / \mathrm{mL}$ ( $58.7 \%$ vs. $10.9 \%$; $p<0.0001)$. Nevertheless, a substantial proportion $(27.8 \%)$ of patients with baseline $\mathrm{HBsAg} \geq 1500 \mathrm{IU} / \mathrm{mL}$ eventually had 
Hu P. et al: High HBsAg loss rates by switching to Peg-IFN



Fig. 2. HBsAg, HBV DNA, and ALT levels of responders (HBsAg loss at end of treatment) 48 weeks after treatment discontinuation. Patients with missing HBsAg data at end of follow-up (four in the week $48 \mathrm{arm}$ and three in the week $96 \mathrm{arm}$ ) are not depicted in this diagram. Dotted lines indicate $\mathrm{HBsAg}$ threshold of $0.05 \mathrm{IU} / \mathrm{mL}$ (blue), HBV DNA $200 \mathrm{IU} / \mathrm{mL}$ (red), and ALT $1 \times$ ULN (green). Abbreviations: ALT, alanine aminotransferase; HBsAg, hepatitis B surface antigen; HBV, hepatitis B virus; PegIFN, pegylated-interferon; ULN, upper limit of normal.

HBsAg cleared at week 48 if HBsAg levels reduced to <200 IU/ $\mathrm{mL}$ at week 24 (Table 3).

In patients who initiated Peg-IFN alfa-2a treatment with HBsAg < $1500 \mathrm{IU} / \mathrm{mL}$ (138/303), although one-third (52/138;
$37.7 \%$ ) did not achieve reduction of HBsAg to $<500 \mathrm{IU} / \mathrm{mL}$ after 12 weeks of treatment, $26.9 \%$ (14/52) of these patients eventually had HBsAg reduced to $<200 \mathrm{IU} / \mathrm{mL}$ at week 24 and had the chance to achieve HBsAg loss at week 48 (Supplementary

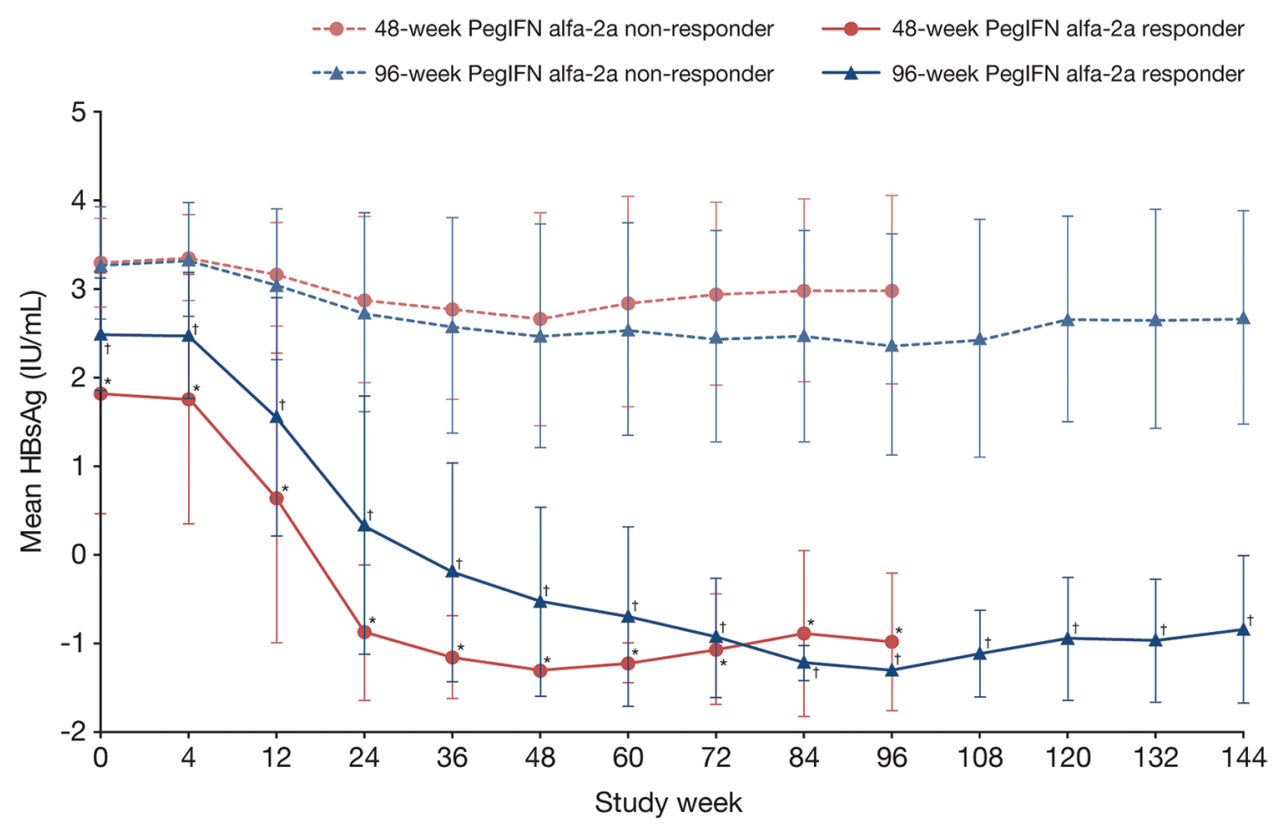

${ }^{*} \mathrm{P}<0.0001$ for 48 -week responder vs. non-responder ${ }^{+} \mathrm{P}<0.0001$ for 96 -week responder vs. non-responder

Fig. 3. Decline in mean serum HBsAg over time with 48 and 96 weeks of Peg-IFN alfa-2a treatment according to response (HBsAg loss at the end of treatment). Data shown are mean \pm standard deviation. Abbreviations: HBsAg, hepatitis B surface antigen; Peg-IFN, pegylated-interferon. 
Hu P. et al: High HBsAg loss rates by switching to Peg-IFN

Table 3. HBsAg loss rates at the end of 48 and 96 weeks of Peg-IFN alfa-2a treatment, according to baseline and on-treatment HBsAg levels

\begin{tabular}{|c|c|c|c|c|c|c|}
\hline & $\begin{array}{l}\text { Baseline } \\
\text { HBsAg, } \\
\text { IU/mL }\end{array}$ & $n / N(\%)$ & $\begin{array}{l}\text { Week } 24 \\
\text { HBsAg, } \\
\text { IU/mL* }\end{array}$ & $n / N(\%)$ & $\begin{array}{l}\text { HBsAg loss } \\
\text { at week } 48, \\
n / N(\%)\end{array}$ & $\begin{array}{l}\text { HBsAg loss at } \\
\text { week } 96, n / N(\%)\end{array}$ \\
\hline \multirow{4}{*}{$\begin{array}{l}\text { Overall population, } \\
n=303\end{array}$} & $<1500$ & $138 / 303(45.5)$ & $<200$ & $81 / 138(58.7)$ & $35 / 81(43.2)$ & \\
\hline & & & $\geq 200$ & $45 / 138(32.6)$ & 0 & \\
\hline & $\geq 1500$ & $165 / 303(54.5)$ & $<200$ & $18 / 165$ (10.9) & $5 / 18(27.8)$ & \\
\hline & & & $\geq 200$ & $142 / 165(86.1)$ & 0 & \\
\hline \multirow{4}{*}{$\begin{array}{l}\text { 48-week Peg-IFN } \\
\text { alfa-2a, } n=153\end{array}$} & $<1500$ & $68 / 153(44.4)$ & $<200$ & $35 / 68(51.5)$ & $18 / 35(51.4)$ & \\
\hline & & & $\geq 200$ & $26 / 68(38.2)$ & 0 & \\
\hline & $\geq 1500$ & $85 / 153(55.5)$ & $<200$ & $10 / 85(11.8)$ & $4 / 10(40.0)$ & \\
\hline & & & $\geq 200$ & $73 / 85$ (85.9) & 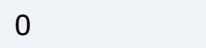 & \\
\hline \multirow{4}{*}{$\begin{array}{l}\text { 96-week Peg-IFN } \\
\text { alfa-2a, } n=150\end{array}$} & $<1500$ & $70 / 150(46.7)$ & $<200$ & $46 / 70(65.7)$ & $17 / 46(37.0)$ & $27 / 46^{\dagger}(58.7)$ \\
\hline & & & $\geq 200$ & $19 / 70(27.1)$ & 0 & $1 / 19(5.3)$ \\
\hline & $\geq 1500$ & $80 / 150(53.3)$ & $<200$ & $8 / 80(10.0)$ & $1 / 8(12.5)$ & $1 / 8(12.5)$ \\
\hline & & & $\geq 200$ & $69 / 80(86.3)$ & 0 & $2 / 69(2.9)$ \\
\hline
\end{tabular}

* 9 and 8 patients in the 48- and 96-week Peg-IFN alfa-2a arms, respectively, had missing data at week 24;

${ }^{\dagger} 13$ responders (HBsAg loss) and 14 nonresponders at week 48 had HBsAg loss at week 96.

Abbreviations: $\mathrm{HBsAg}$, hepatitis B surface antigen; Peg-IFN, pegylated-interferon.

Table 3). As such, HBsAg $<200 \mathrm{IU} / \mathrm{mL}$ was the most important predictor of HBsAg loss at week 48.

Baseline HBsAg < $1500 \mathrm{IU} / \mathrm{mL}$ and week $24 \mathrm{HBsAg}<200 \mathrm{IU} /$ $\mathrm{mL}$ were associated with the highest rates of HBsAg loss at the end of both 48- and 96-week Peg-IFN alfa-2a treatment, while baseline $\mathrm{HBsAg} \geq 1500 \mathrm{IU} / \mathrm{mL}$ and week $24 \mathrm{HBsAg} \geq 200 \mathrm{IU} / \mathrm{mL}$ were associated with the lowest rates of HBsAg loss (Table 3 ). After 48 weeks of treatment, HBsAg loss rates were similar between patients in the 48- and 96-week arms (51.4\% [18/35] and $37.0 \%$ [17/46]; $p=0.2582$ ). Importantly, among the 29 patients in the 96-week arm whose HBsAg did not clear at week 48 , extended treatment up to 96 weeks enabled $48.3 \%(n=14)$ more patients to achieve HBsAg loss.

\section{Safety}

More patients required dose reductions over the 96-week course of treatment $(18.7 \%)$ than the 48 -week course of treatment $(11.1 \%)$. The most common adverse events in the safety population were those known to be associated with interferonbased therapy, including leukopenia $(45.2 \%)$, neutropenia $(39.6 \%)$, fever $(39.6 \%)$, and thrombocytopenia (28.7\%). Psychiatric adverse events were observed in 16 patients (5.3\%) and included insomnia, anxiety symptoms, depressed mood disorders, and mood changes; all except one severe case of decreased libido were either mild or moderate. ALT flare $(>5 \times$ ULN) was observed in two patients at the end of 48-week followup; both cases were preceded by virological relapse.

Eight cases of treatment-related serious adverse events were reported in six patients: one in the 48-week treatment arm and five in the 96-week treatment arm. All events were resolved following Peg-IFN alfa-2a dose adjustment or withdrawal. No deaths occurred (Table 4).

\section{Discussion}

The New Switch study evaluated HBsAg loss as the primary endpoint in NA-treated $\mathrm{HBeAg}$-positive $\mathrm{CHB}$ patients who switched to Peg-IFN alfa-2a. In our study, we assessed HBsAg loss in NA-treated patients for whom rates are typically low, particularly in Asian patients. While the impact of HBV genotype on response to NA therapy has not been established, findings from several studies have indicated that patients infected with genotype B or $\mathrm{C}$, the most common HBV strains in China, had a lower chance of achieving HBsAg loss with NA therapy than those infected with genotype A or D. ${ }^{23-25}$ Typical HBsAg loss rates with NAs are $0-3 \%$ after a year of treatment and up to $8 \%$ after 3 years of continuous tenofovir disoproxil fumarate treatment. ${ }^{26-30}$ We included patients who had already achieved HBeAg loss as it is associated with increased chance of subsequent HBsAg loss during or after Peg-IFN alfa2a treatment. ${ }^{19,20}$

Strategies to optimize HBsAg loss in NA-treated patients include switching to or adding on Peg-IFN alfa-2a, which has demonstrated significantly increased HBsAg loss versus continuing NA monotherapy. Peg-IFN alfa-2a has also been investigated in add-on strategies to optimize HBsAg loss in NA-treated $\mathrm{CHB}$ patients in the PEGAN and ARES studies, demonstrating increased HBsAg loss rates compared with NA monotherapy. ${ }^{31-34}$ However, we chose to explore the optimal duration of Peg-IFN alfa-2a treatment for NA-treated patients with a switch strategy, rather than an add-on strategy, as the switch strategy allows patients to achieve sustained HBsAg loss and eventually discontinue treatment altogether, rather than continuing NA indefinitely to maintain virological suppression with an add-on strategy.

In this final analysis, more previously NA-treated patients who received an extended duration (96 weeks) of Peg-IFN alfa2a treatment achieved HBsAg loss and seroconversion than those who received 48 weeks of Peg-IFN alfa-2a, although differences were not statistically significant. Our study supports findings from the OSST study, which showed that $8.5 \%$ and $4.3 \%$ of patients who switched from entecavir to 48-week PegIFN alfa-2a treatment achieved HBsAg loss and HBsAg seroconversion, respectively, while none of those who continued on entecavir achieved either of the outcomes. ${ }^{19}$ Similarly, the 
Hu P. et al: High HBsAg loss rates by switching to Peg-IFN

Table 4. Safety outcomes following 48 and 96 weeks of Peg-IFN alfa-2a treatment

\begin{tabular}{|c|c|c|}
\hline Variable, $n(\%)$ & 48-week Peg-IFN alfa-2a, $n=153$ & 96-week Peg-IFN alfa-2a, $n=150$ \\
\hline Dose reduction* & $17(11.1)$ & $28(18.7)$ \\
\hline Thrombocytopenia & $10(6.5)$ & $14(9.3)$ \\
\hline Neutropenia & $6(3.9)$ & $11(7.3)$ \\
\hline ALT increased & $1(0.7)$ & $3(2.0)$ \\
\hline Other & $4(2.6)$ & $6(4.0)$ \\
\hline Death & 0 & 0 \\
\hline$\geq 1$ adverse event & $135(88.2)$ & $140(93.3)$ \\
\hline Treatment-related adverse event & $131(85.6)$ & $136(90.7)$ \\
\hline$\geq 1$ serious adverse event & $4(2.6)$ & $7(4.7)$ \\
\hline Treatment-related serious adverse event & $1(0.7)$ & $5(3.3)$ \\
\hline \multicolumn{3}{|l|}{ Adverse events ${ }^{\dagger}$} \\
\hline Leukopenia & $70(45.8)$ & $67(44.7)$ \\
\hline Neutropenia & $58(37.9)$ & $62(41.3)$ \\
\hline Fever & $60(39.2)$ & $60(40.0)$ \\
\hline Thrombocytopenia & $45(29.4)$ & $42(28.0)$ \\
\hline Fatigue & $35(22.9)$ & $37(24.7)$ \\
\hline ALT increased & $34(22.2)$ & $28(18.7)$ \\
\hline Alopecia & $27(17.6)$ & $29(19.3)$ \\
\hline AST increased & $25(16.3)$ & $26(17.3)$ \\
\hline Abnormal liver function & $19(12.4)$ & $22(14.7)$ \\
\hline Headache & $19(12.4)$ & $20(13.3)$ \\
\hline Influenza-like illness & $13(8.5)$ & $21(14.0)$ \\
\hline
\end{tabular}

* Patients may have had more than one reason for reducing dose of study drug;

${ }^{\dagger}$ Patients may have had more than one adverse event. Events listed are those with an incidence of at least $10 \%$.

Abbreviations: ALT, alanine aminotransferase; AST, aspartate aminotransferase; Peg-IFN, pegylated-interferon.

SWAP study conducted in Singapore in patients who achieved undetectable HBV DNA with or without HBeAg loss showed that $8.9 \%$ of patients on long-term NA therapy who switched to 48 week Peg-IFN cleared HBsAg 6 months' post-treatment, while none of those who continued on NAs did. ${ }^{35}$ We also demonstrated higher HBsAg loss rates than in the OSST study. In contrast to the patients in the OSST study, who had low HBeAg levels $(<100 \mathrm{PE} \mathrm{IU} / \mathrm{mL})$ at baseline, patients in our study are a further selected population who had achieved $\mathrm{HBeAg}$ loss at baseline and potentially have better host immune status.

Our study demonstrated that HBsAg loss with Peg-IFN alfa$2 \mathrm{a}$ is durable, with over $70 \%$ of patients sustaining response 48 weeks after treatment discontinuation. Among patients who did not sustain response post-treatment, most had HBsAg levels below $10 \mathrm{IU} / \mathrm{mL}$, and none experienced virological relapse. The mechanism of HBsAg relapse among these patients is not clear due to the limited number of patients who did not sustain HBsAg loss. We endeavor to continue following up patients in our study to collect more information.

The optimal strategy for maximizing the chance of HBsAg loss through Peg-IFN alfa-2a in NA-treated patients remains to be determined. Early on-treatment HBsAg quantification has demonstrated to be useful in individualized on-treatment decision-making for $\mathrm{HBeAg}$-positive patients. On-treatment HBsAg decline has been shown to be useful for predicting eventual HBsAg loss and determining the optimal duration of Peg-IFN add-on therapy in a small cohort of patients. ${ }^{31}$ Consistent with previous studies, ${ }^{19,36}$ our study found that patients with a combined baseline HBsAg level of $<1500 \mathrm{IU} / \mathrm{mL}$ and week $24 \mathrm{HBsAg}$ level of $<200 \mathrm{IU} / \mathrm{mL}$ had the highest chance of achieving HBsAg loss at the end of Peg-IFN alfa-2a treatment.

We also found that among patients with baseline $\mathrm{HBsAg}$ levels below $1500 \mathrm{IU} / \mathrm{mL}$ and week $24 \mathrm{HBsAg}$ levels below 200 $\mathrm{IU} / \mathrm{mL}$, extending Peg-IFN alfa-2a treatment from 48 to 96 weeks enabled approximately $50 \%$ more patients to achieve HBsAg loss, although between-group differences were not statistically significant in the overall population. Similarly, among patients who had the lowest chance of achieving HBsAg loss at the end of treatment (i.e. those with week 24 HBsAg level of $\geq 200 \mathrm{IU} / \mathrm{mL}$ ), none in the 48 -week treatment group cleared HBsAg at end of treatment; however, extending treatment to 96 weeks allowed three patients to clear HBsAg, although it is uncertain if this was a result of active treatment or spontaneous resolution. Furthermore, while mean $\mathrm{HBsAg}$ levels increased in all patients who did not achieve HBsAg loss after treatment was discontinued, the increase was more marked in patients treated for only 48 weeks compared with those treated for an extended 96-week duration.

While ALT flares are typically regarded as host induced and reflect immune clearance of HBV, it occurred in two patients in our study after 48-week follow-up and was preceded by virological relapse. This highlights the importance of monitoring and repeat testing of viral load to allow timely adjustments in treatment regimens and prevent hepatitis flares. Similarly, 
patients who do not achieve HBsAg loss at the end of Peg-IFN alfa-2a treatment should be followed up closely and monitored for virological relapse, in which case it may be appropriate to start NA therapy again.

Peg-IFN alfa-2a was generally well tolerated and the safety profile was similar to that reported in other investigations of adding or switching to Peg-IFN alfa-2a. ${ }^{19,34}$ Extending treatment from 48 to 96 weeks did not appear to increase the incidence of adverse events.

A limitation of our study is the lack of information regarding treatment response to prior NA therapy, such as on-treatment HBV DNA and HBsAg kinetics, as well as HBV genotype, which could not be obtained at enrollment as most patients had undetectable or low levels of HBV DNA. These may impact subsequent response after switching to Peg-IFN alfa-2a. There was neither a blank control nor a continued NA control arm as it would have been unethical because of the associated high relapse rates and low chance of HBsAg loss relative to Peg-IFN alfa-2a treatment. Continued NA therapy among patients with low HBeAg and HBV DNA levels had already been evaluated in the OSST study, which demonstrated that none of the patients who continued NA achieved HBsAg loss; therefore, our study focused on evaluating the optimal treatment duration for switched patients. Biopsy was not performed and thus it is unknown if covalently closed circular DNA was eradicated and if indeed virological cure was achieved in patients with $\mathrm{HBsAg}$ clearance. Findings from this study may only be applicable to regions such as Asia where HBV genotypes $B$ and $C$ are common, rather than to regions where genotypes $A$ and $D$ are prevalent. Finally, longer-term follow-up and testing of immune parameters should be investigated to further inform which NAtreated patients can benefit most from switching to Peg-IFN alfa-2a.

\section{Conclusions}

The New Switch study has provided essential data on how patients who are currently receiving NAs can maximize their chances of achieving HBsAg loss by switching to finite PegIFN alfa-2a treatment. This analysis showed that sustained HBsAg loss is attainable in NA-treated patients who switch to Peg-IFN alfa-2a therapy. Extending treatment duration from 48 to 96 weeks may allow some patients a higher chance of achieving HBsAg loss, although this outcome was not statistically significant among the overall population in our study, while baseline and early on-treatment quantitative HBsAg levels may predict which patients have the highest likelihood of achieving HBsAg loss with Peg-IFN alfa-2a treatment and identify selected patients who may benefit from extended treatment.

\section{Acknowledgments}

The authors would like to thank the patients and their families for their contribution to this study. This study was supported by the National Science and Technology Major Project of China (2008ZX10002-006, 2012ZX10002007001, 2017ZX10202203-007, 2017ZX10202203-008) and the National Natural Science Foundation of China (81171561, 30972584). This study was also supported in part by Shanghai Roche Pharmaceuticals Ltd. Writing assistance was provided by Stefanie Chuah, from Mudskipper Business Ltd, funded by F Hoffmann-La Roche.

\section{Conflict of interest}

Prof. Hou has received grant/research support from Gilead, Novartis, Bristol-Myers Squibb and GlaxoSmithKline, and consulting fees from Gilead. Prof. Ren has received grant/ research support from Roche, Novartis, Bristol-Myers Squibb and GlaxoSmithKline. None of the other authors have no conflict of interests related to this publication.

\section{Author contributions}

Made substantial contributions to conception and design of the study, and analysis and interpretation of the study data $(\mathrm{PH}, \mathrm{JS}, \mathrm{WZ}, \mathrm{HR})$, drafted the manuscript $(\mathrm{PH}, \mathrm{HR})$, obtained funding to support the study (HR). All authors made substantial contributions to acquisition of data and critical revision of the manuscript for important intellectual content.

\section{References}

[1] EASL 2017 Clinical Practice Guidelines on the management of hepatitis B virus infection. J Hepatol 2017;67:370-398. doi: 10.1016/j.jhep.2017.03.021.

[2] Lu FM, Li T, Liu S, Zhuang H. Epidemiology and prevention of hepatitis B virus infection in China. J Viral Hepat 2010;17:4-9. doi: 10.1111/j.1365-2893. 2010.01266.x.

[3] Ott J], Stevens GA, Groeger J, Wiersma ST. Global epidemiology of hepatitis B virus infection: new estimates of age-specific HBsAg seroprevalence and endemicity. Vaccine 2012;30:2212-2219. doi: 10.1016/j.vaccine.2011.12.116.

[4] Terrault NA, Bzowej NH, Chang KM, Hwang JP, Jonas MM, Murad MH. AASLD guidelines for treatment of chronic hepatitis B. Hepatology 2016;63:261283. doi: 10.1002/hep.28156.

[5] Sarin SK, Kumar M, Lau GK, Abbas Z, Chan HL, Chen C], et al. Asian-Pacific clinical practice guidelines on the management of hepatitis B: a 2015 update. Hepatol Int 2016;10:1-98. doi: 10.1007/s12072-015-9675-4.

[6] Fung SK, Wong F, Hussain M, Lok AS. Sustained response after a 2-year course of lamivudine treatment of hepatitis $B$ e antigen-negative chronic hepatitis B. J Viral Hepat 2004;11:432-438. doi: 10.1111/j.1365-2893.2004. 00556.x.

[7] Seto WK, Hui AJ, Wong VW, Wong GL, Liu KS, Lai CL, et al. Treatment cessation of entecavir in Asian patients with hepatitis $B$ e antigen negative chronic hepatitis B: a multicentre prospective study. Gut 2015;64:667-672. doi: 10 . 1136/gutjnl-2014-307237.

[8] Liu F, Wang L, Li XY, Liu YD, Wang JB, Zhang ZH, et al. Poor durability of lamivudine effectiveness despite stringent cessation criteria: a prospective clinical study in hepatitis B e antigen-negative chronic hepatitis B patients. J Gastroenterol Hepatol 2011;26:456-460. doi: 10.1111/j.1440-1746.2010. 06492.x.

[9] Chaung KT, Ha NB, Trinh HN, Garcia RT, Nguyen HA, Nguyen KK, et al. High frequency of recurrent viremia after hepatitis $\mathrm{B}$ e antigen seroconversion and consolidation therapy. J Clin Gastroenterol 2012;46:865-870. doi: 10. 1097/MCG.0b013e31825ceed9.

[10] Dai CY, Tseng TC, Wong GL, Huang JF, Wong VW, Liu CJ, et al. Consolidation therapy for $\mathrm{HBeAg}$-positive Asian chronic hepatitis $\mathrm{B}$ patients receiving lamivudine treatment: a multicentre study. J Antimicrob Chemother 2013;68: 2332-2338. doi: 10.1093/jac/dkt193.

[11] Lee HW, Lee HJ, Hwang JS, Sohn JH, Jang JY, Han KJ, et al. Lamivudine maintenance beyond one year after HBeAg seroconversion is a major factor for sustained virologic response in $\mathrm{HBeAg}$-positive chronic hepatitis B. Hepatology 2010;51:415-421. doi: 10.1002/hep.23323.

[12] Block TM, Gish R, Guo H, Mehta A, Cuconati A, Thomas London W, et al. Chronic hepatitis $B$ : what should be the goal for new therapies? Antiviral Res 2013;98:27-34. doi: 10.1016/j.antiviral.2013.01.006.

[13] Chen YC, Sheen IS, Chu CM, Liaw YF. Prognosis following spontaneous HBsAg seroclearance in chronic hepatitis B patients with or without concurrent infection. Gastroenterology 2002;123:1084-1089. doi: 10.1053/gast. 2002.36026

[14] Moucari R, Korevaar A, Lada O, Martinot-Peignoux M, Boyer N, Mackiewicz V, et al. High rates of HBsAg seroconversion in HBeAg-positive chronic hepatitis $B$ patients responding to interferon: a long-term follow-up study. J Hepatol 2009;50:1084-1092. doi: 10.1016/j.jhep.2009.01.016.

[15] Lau GK, Piratvisuth T, Luo KX, Marcellin P, Thongsawat S, Cooksley G, et al. Peginterferon Alfa-2a, lamivudine, and the combination for HBeAg-positive chronic hepatitis B. N Engl J Med 2005;352:2682-2695. doi: 10.1056/ NEJMoa043470. 
[16] Janssen HL, van Zonneveld M, Senturk H, Zeuzem S, Akarca US, Cakaloglu Y, et al. Pegylated interferon alfa-2b alone or in combination with lamivudine for HBeAg-positive chronic hepatitis B: a randomised trial. Lancet 2005;365: 123-129. doi: 10.1016/S0140-6736(05)17701-0.

[17] Marcellin P, Bonino F, Yurdaydin C, Hadziyannis S, Moucari R, Kapprell HP, et al. Hepatitis $B$ surface antigen levels: association with 5 -year response to peginterferon alfa- $2 a$ in hepatitis $B$ e-antigen-negative patients. Hepatol Int 2013;7:88-97. doi: 10.1007/s12072-012-9343-x.

[18] Chevaliez S, Hézode C, Bahrami S, Grare M, Pawlotsky JM. Long-term hepatitis $B$ surface antigen (HBsAg) kinetics during nucleoside/nucleotide analogue therapy: finite treatment duration unlikely. J Hepatol 2013;58:676-683. doi: 10.1016/j.jhep.2012.11.039.

[19] Ning Q, Han M, Sun Y, Jiang J, Tan D, Hou J, et al. Switching from entecavir to PegIFN alfa-2a in patients with HBeAg-positive chronic hepatitis B: a randomised open-label trial (OSST trial). J Hepatol 2014;61:777-784. doi: 10. 1016/j.jhep.2014.05.044.

[20] van Zonneveld M, Honkoop P, Hansen BE, Niesters HG, Darwish Murad S, de Man RA, et al. Long-term follow-up of alpha-interferon treatment of patients with chronic hepatitis B. Hepatology 2004;39:804-810. doi: 10.1002/hep. 20128.

[21] Lampertico P, Viganò M, Di Costanzo GG, Sagnelli E, Fasano M, Di Marco V, et al. Randomised study comparing 48 and 96 weeks peginterferon $\alpha-2 a$ therapy in genotype D HBeAg-negative chronic hepatitis B. Gut 2013;62: 290-298. doi: 10.1136/gutjnl-2011-301430.

[22] Zhu YY, Wu YL, Chen J, Zheng Q, Dong J, Jiang JJ. Prolonged duration of the routine pegylated-interferon alfa-2a therapy produces superior virological response in $\mathrm{HBeAg}$-positive chronic hepatitis $\mathrm{B}$ patients: a single-center cohort study. Zhonghua Gan Zang Bing Za Zhi 2012;20:737-741. doi: 10. 3760/cma.j.issn.1007-3418.2012.10.006.

[23] Sunbul M. Hepatitis B virus genotypes: global distribution and clinical importance. World J Gastroenterol 2014;20:5427-5434. doi: 10.3748/wjg.v20. i18.5427.

[24] Zoulim F, Carosi G, Greenbloom S, Mazur W, Nguyen T, Jeffers L, et al. Quantification of HBsAg in nucleos(t)ide-naïve patients treated for chronic hepatitis $B$ with entecavir with or without tenofovir in the BE-LOW study. J Hepatol 2015;62:56-63. doi: 10.1016/j.jhep.2014.08.031.

[25] Marcellin P, Buti M, Krastev Z, de Man RA, Zeuzem S, Lou L, et al. Kinetics of hepatitis $B$ surface antigen loss in patients with $\mathrm{HBeAg-positive} \mathrm{chronic} \mathrm{hep-}$ atitis B treated with tenofovir disoproxil fumarate. J Hepatol 2014;61:12281237. doi: $10.1016 / j$.jhep.2014.07.019.

[26] Marcellin P, Heathcote EJ, Buti M, Gane E, de Man RA, Krastev Z, et al. Tenofovir disoproxil fumarate versus adefovir dipivoxil for chronic hepatitis B. N Engl J Med 2008;359:2442-2455. doi: 10.1056/NEJMoa0802878.
[27] Lai CL, Chien RN, Leung NW, Chang TT, Guan R, Tai DI, et al. A one-year trial of lamivudine for chronic hepatitis B. Asia Hepatitis Lamivudine Study Group. N Engl J Med 1998;339:61-68. doi: 10.1056/NEJM199807093390201.

[28] Lai CL, Gane E, Liaw YF, Hsu CW, Thongsawat S, Wang Y, et al. Telbivudine versus lamivudine in patients with chronic hepatitis B. N Engl J Med 2007; 357:2576-2588. doi: 10.1056/NEJMoa066422.

[29] Chang TT, Gish RG, de Man R, Gadano A, Sollano J, Chao YC, et al. A comparison of entecavir and lamivudine for $\mathrm{HBeAg}$-positive chronic hepatitis $\mathrm{B}$. N Engl J Med 2006;354:1001-1010. doi: 10.1056/NEJMoa051285.

[30] Heathcote EJ, Marcellin P, Buti M, Gane E, De Man RA, Krastev Z, et al. Threeyear efficacy and safety of tenofovir disoproxil fumarate treatment for chronic hepatitis B. Gastroenterology 2011;140:132-143. doi: 10.1053/j. gastro.2010.10.011.

[31] Kittner JM, Sprinzl MF, Grambihler A, Weinmann A, Schattenberg JM, Galle $\mathrm{PR}$, et al. Adding pegylated interferon to a current nucleos(t)ide therapy leads to HBsAg seroconversion in a subgroup of patients with chronic hepatitis B. J Clin Virol 2012;54:93-95. doi: 10.1016/j.jcv.2012.01.024.

[32] Ouzan D, Pénaranda G, Joly H, Khiri H, Pironti A, Halfon P. Add-on peginterferon leads to loss of $\mathrm{HBsAg}$ in patients with $\mathrm{HBeAg}$-negative chronic hepatitis and HBV DNA fully suppressed by long-term nucleotide analogs. J Clin Virol 2013;58:713-717. doi: 10.1016/j.jcv.2013.09.020.

[33] Bourlière M, Rabiega P, Ganne-Carrie N, Serfaty L, Marcellin P, Barthe Y, et al. Effect on HBs antigen clearance of addition of pegylated interferon alfa-2a to nucleos(t)ide analogue therapy versus nucleos(t)ide analogue therapy alone in patients with $\mathrm{HBe}$ antigen-negative chronic hepatitis $\mathrm{B}$ and sustained undetectable plasma hepatitis B virus DNA: a randomised, controlled, open-label trial. Lancet Gastroenterol Hepatol 2017;2:177-188. doi: 10.1016/S24681253(16)30189-3.

[34] Brouwer WP, Xie Q, Sonneveld MJ, Zhang N, Zhang Q, Tabak F, et al. Adding pegylated interferon to entecavir for hepatitis $B$ e antigen-positive chronic hepatitis B: A multicenter randomized trial (ARES study). Hepatology 2015; 61:1512-1522. doi: 10.1002/hep.27586.

[35] Lim SG, Yang WL, Ngu J, Tan J, Ahmed TT, Dan YY, et al. Switch or add-on peginterferon for chronic hepatitis $B$ patients already on nucleos(t)ide analogue therapy (SWAP study): provisional analysis - add-on therapy superior. J Hepatol 2017;66:S60. doi: 10.1016/S0168-8278(17)30382-3.

[36] Sonneveld MJ, Hansen BE, Piratvisuth T, Jia JD, Zeuzem S, Gane E, et al. Response-guided peginterferon therapy in hepatitis $B$ e antigen-positive chronic hepatitis B using serum hepatitis B surface antigen levels. Hepatology $2013 ; 58$ : 872-880. doi: 10.1002/hep.26436. 